\title{
The response of ocean parameters to tropical cyclones in the Bay of Bengal
}

\author{
Nanda Kishore Reddy Busireddy ${ }^{1,2}$ | Kumar Ankur $^{1}{ }^{(D)}$ | Krishna Kishore Osuri ${ }^{1}$ (D) | \\ Sanikommu Sivareddy ${ }^{3,4}$ (i) | Dev Niyogi ${ }^{2}$ (i)
}

${ }^{1}$ Department of Earth and Atmospheric Sciences, National Institute of Technology Rourkela, Odisha, India

${ }^{2}$ Department of Agronomy and Department of Earth Atmospheric and Planetary Sciences, Purdue University, West Lafayette, Indiana

${ }^{3}$ Modeling and Data Assimilation Group, Indian National Centre for Ocean

Information Services, Hyderabad, India

${ }^{4}$ Computer, Electrical and Mathematical Sciences and Engineering (CEMSE) Division, King Abdullah University of Science and Technology (KAUST), Thuwal, Kingdom of Saudi Arabia

\section{Correspondence}

Krishna Kishore Osuri, Department of Earth and Atmospheric Sciences, National Institute of Technology, Rourkela, Odisha 769008, India.

Email: osurikishore@gmail.com

\begin{abstract}
The Bay of Bengal (BoB) exhibits notable seasonal variations in tropical cyclone heat potential (TCHP), barrier layer thickness (BLT) and sea-surface temperature (SST). These parameters also undergo profound changes in the presence of tropical cyclones (TCs). The composite structures of these ocean parameters as a function of the season of TC formation, intensity, and translation speed are unknown and are developed in the present study. Composite structures are examined based on 1,222 instantaneous samples from 83 TCs during 2003-2016 using INCOIS-GODAS analyses. A BLT of $10-30 \mathrm{~m}$ and TCHP of $40-80 \mathrm{~kJ} / \mathrm{cm}^{2}$ favours TC intensification in the central BoB. The multivariate regression of BLT and TCHP appears to be better for TC intensity up to 64 knots and is highly underestimated for the stronger TCs ( $>64$ knots). The TC right-rear sector experiences significant changes in TCHP anomaly (TCHPA) as the intensity increases. The TCHPA ranges $\sim 10-15, \sim 20-25$ and $\sim 25-30 \mathrm{~kJ} / \mathrm{cm}^{2}$ when a TC is at Cyclone Storm (CS), Severe Cyclonic Storm (SCS) and Very SCS (VSCS) stages respectively. The maximum TCHPA is generally aligned along the TC track during the post-monsoon season. Slow-moving TCs produce maximum TCHPA cooling of $\sim 20 \mathrm{~kJ} / \mathrm{cm}^{2}$ within $250 \mathrm{~km}$ storm radius in the rear sector, while it is less and away from the storm centre for normal and fast-movers. The seasonal changes showed opposite relations between BLT and TCHP from pre- to post-monsoon seasons during the TC intensification. TC-induced SST cooling is maximum $\left(\sim 0.5-1.2^{\circ} \mathrm{C}\right)$ in the inner core for the strong (VSCS and above) and slow-moving TCs. The cooling decreases with an increase in the translation speed and is more pronounced in the pre-monsoon season. This study provides a baseline to verify and understand the limitations of the models, and also develop a climatological perspective of BoB TCs.
\end{abstract}

\section{K E Y W O R D S}

Bay of Bengal, sea-surface temperature, translation speed, tropical cyclone heat potential, tropical cyclones 


\section{1 | INTRODUCTION}

The Bay of Bengal (BoB) in the tropical North Indian Ocean shows more pronounced tropical cyclones (TCs) with a frequency of almost five times as compared to the Arabian Sea (India Meteorological Department, 2008). These TCs exhibit a bimodal TC activity with a primary maximum during the post-monsoon season (October to December), followed by a secondary peak during the pre-monsoon season (April-May). The general direction of movement of TCs is northwest during the post-monsoon season and north and northeastward with recurving nature in the pre-monsoon season (Mohapatra et al., 2013a; Osuri et al., 2013). A characteristic peculiarity of the $\mathrm{BoB}$ is the highly stratified region. Large freshwater discharge from the surrounding rivers and heavy rainfall set a significant salinity stratification near the surface and give rise to a thick barrier layer in the ocean (McPhaden et al., 2009; Fu et al., 2014). The definition of the barrier layer is the region between the base of the mixed layer to the bottom of the isothermal layer (Balaguru et al., 2012). Also, it exhibits seasonal variation showing strong stratification (and thick barrier layer) in the post-monsoon season and less stratification (thin barrier layer) in the pre-monsoon season $(\mathrm{Li}$ et al., 2017). Therefore, considering this fact, post-monsoon TCs are relatively stronger than those in the pre-monsoon season (Mohapatra et al., 2013b). In addition, the prominent feature of this thick barrier layer (BL) is that it can preserve more heat content (in the layer from the surface to a depth of $26{ }^{\circ} \mathrm{C}$ isotherm), which is recognized as one of the important ocean parameters for TC evolution (Leipper and Volgenau, 1972; Shay et al., 2000; Goni and Trinanes, 2003). Due to its high relevance to the formation of the TC, the heat content is referred to as the tropical cyclone heat potential (TCHP) in the literature (Leipper and Volgenau, 1972; Goni and Trinanes, 2003; Busireddy et al., 2018). Many recent studies discuss the significance of the TCHP in the TC movement and intensity evolution (Goni and Trinanes, 2003; Lin et al., 2009a; 2013; Krishnamurti et al., 2017; Yan et al., 2017). Lin et al. (2008), for example, described that the pre-existing TCHP of $77-105 \mathrm{~kJ} / \mathrm{cm}^{2}$ was responsible for the TC Nargis rapid intensification process over the BoB. As the TC intensifies, its influence is not only limited to the ocean surface, it also affects the upper ocean column (Goni and Trinanes, 2003; Lin et al., 2008). Moreover, BoB is an eddy-rich region that modulates the TCHP, BLT and sea-surface temperature (SST) in the presence of mesoscale eddies (Ali et al., 1998; Busireddy et al., 2018), which in turn contribute to the growth/decay of ocean vortices.

The SST greatly affects and is in turn affected by the TC intensity (Black, 1983; Lin et al., 2008). Strong winds associated with the TC cause vigorous mixing in the upper ocean, resulting in surface cooling changes along the track as well as several hundred kilometres away from the TC centre (D'Asaro et al., 2007; Foltz and McPhaden, 2009; Dare and McBride, 2011). Mei et al. (2012) reported that the TC intensification rate and amplitude of SST anomaly (SSTA) are directly related to each other. A negative SSTA (cooling) of $\sim 3-5{ }^{\circ} \mathrm{C}$ was observed near a hurricane track over the Atlantic basin (Leipper and Volgenau, 1972) and $3{ }^{\circ} \mathrm{C}$ over the Pacific basin (Wright, 1969). Similarly, an SST cooling of $\sim 5-6{ }^{\circ} \mathrm{C}$ was observed during the Orissa super-cyclone (1999) over the BoB (Sadhuram, 2004). The SSTA also shows significant seasonal variations in the BoB. Sengupta et al. (2008) analysed 14 TCs during the period 1998-2004 and reported SST cooling of $\sim 2{ }^{\circ} \mathrm{C}$ or more for the pre-monsoon as compared to post-monsoon season over the BoB. The translation speed of the TCs also plays a significant role in modulating the SSTA (Mei et al., 2012). Considering the SST feedbacks, slower (faster) moving TCs leads to relatively stronger (weaker) negative SSTA (Zedler, 2009). Studies such as Pothapakula et al. (2017) concluded that slow and pre-monsoon storms produce higher SST cooling of $\sim 2{ }^{\circ} \mathrm{C}$ than that of the post-monsoon season in the BoB. As a feedback reverse, the amplitude of the storm-induced SSTA affects translation speed and thereby the TC evolution (Zedler, 2009; Mei et al., 2012; Pothapakula et al., 2017).

The objective of this study is to reconcile and improve the understanding of the relationship of BL, TCHP and SST with $\mathrm{TC}$ evolution over the BoB. To that end, the present study analyses the composite structures of ocean parameters (such as TCHP, SST, BL) as a function of TC intensity, the season of TC formation and their translation speed. The average strength of the TC-induced cooling is also analysed by the superposition of the effect due to the storm intensity and translation speed. The studies describing the composite radial structures of these parameters to the TC evolution are limited or not available over the $\mathrm{BoB}$, and are, therefore, considered as another objective of the current study. Comprehensive quantification of these characteristic features of the ocean parameters and the interrelationships among them are studied based on a large number of cases (1,222 samples from 83 TCs) during 2003-2016.

\section{2 | DATA AND METHODOLOGY}

An ocean analysis prepared from the Global Ocean Data Assimilation System (GODAS: Ravichandran et al., 2013; Sivareddy, 2015) at the Indian National Centre for Ocean Information Services (INCOIS) is used for this analysis. The GODAS is adopted from the National Centers for Environmental Prediction and coupled with the Ocean General Circulation Model (OGCM), the Modular Ocean Model (MOM) version 4.0 (hereafter referred to as INCOIS-GODAS). The OGCM has a uniform zonal resolution of $0.5^{\circ}$. The meridional resolution is $0.25^{\circ}$ up to $10^{\circ} \mathrm{N} / \mathrm{S}$ from the Equator and decreases exponentially up to $30^{\circ} \mathrm{N} / \mathrm{S}$, and beyond $30^{\circ} \mathrm{N} / \mathrm{S}$ a 
uniform resolution of $0.5^{\circ}$ is maintained. There are 40 layers in the vertical direction with the top 24 layers placed every $10 \mathrm{~m}$. The model integration time step is $30 \mathrm{~min}$. The model is forced with the Indian National Centre for Medium Range Weather Forecasting (NCMRWF) atmospheric fluxes available at $0.25 \times 0.25^{\circ}$ resolution, four times a day. The INCOIS-GODAS assimilates the observed in situ temperature and salinity profiles within $60^{\circ} \mathrm{S}-60^{\circ} \mathrm{N}$ and from the surface to $750 \mathrm{~m}$ depth. Argo observations within \pm 10 days of analysis time are used. It is noted that the tropical mooring observations are not assimilated in the present analyses to avoid assimilation shocks (Sivareddy et al., 2017). The quality of INCOIS-GODAS analyses has been assessed in various assessments (e.g. Ravichandran et al., 2013; Sivareddy, 2015; Sivareddy et al., 2017) including for tropical cyclone studies (Pothapakula et al., 2017). For instance, the INCOIS-GODAS compared to the in situ observations show a better SST representation with a root-mean-square error (RMSE) of 0.26 and $0.48{ }^{\circ} \mathrm{C}$, respectively, for the pre- and post-monsoon seasons over the BoB (Pothapakula et al., 2017).

The analysis is converted to storm-relative coordinates up to a radial distance of $400 \mathrm{~km}$, from the TC centre in $1^{\circ}$ azimuthal angle, with $10 \mathrm{~km}$ wide annular intervals. Note that the coordinates are aligned in such a way that the direction of the TC motion coincides with the north direction (Lonfat et al., 2004). A total of 1,222 individual samples (in 6-hourly intervals) obtained from all the 83 TCs during 2003-2016 (14 years) are used in the analyses. The TC observed position and intensity (maximum surface wind speed (MSW) and pressure drop) are obtained from the best-track dataset of India Meteorological Department (IMD), available at http://www. rsmcnewdelhi.imd.gov.in.

TCs undergoes different intensity stages, and these stages are classified primarily based on $10 \mathrm{~m}$ maximum surface wind speed (MSW) (Osuri et al., 2013). The intensity classification includes depression and deep depression (DD) if MSW is $17-33$ knots $(1 \mathrm{knot}=0.514 \mathrm{~m} / \mathrm{s})$; cyclonic storm (CS) if MSW is 34-47 knots; severe cyclonic storm (SCS) if MSW is 48-63 knots; very SCS (VSCS) if MSW is 64-89 knots; extremely SCS (ESCS) if MSW is 90-119 knots; and super-cyclonic storm (SuCS) if MSW is 120 knots or more. Further, TCs can be designated as slow-moving TCs if translation speed is $\leq 3 \mathrm{~m} / \mathrm{s}$, normal moving TCs if translation speed lies between 4 and $7 \mathrm{~m} / \mathrm{s}$, and fast-moving TCs if translation speed $>7 \mathrm{~m} / \mathrm{s}$ (Chan and Gray, 1982). Translational speed is calculated based on the average speed in $6 \mathrm{~h}$, specifically from 3 hours before to 3 hours after the analysis time (Mei et al., 2012). Note that the barrier layer thickness (BLT) and TCHP are estimated following the approaches outlined in studies such as Leipper and Volgenau (1972), Sprintall and Tomczak (1992), Shay et al. (2000) and Balaguru et al. (2012). The formulae used for estimating the BLT and TCHP are as follows.

BLT $=$ Isothermal layer depth-Mixed layer depth,

$$
T C H P=\rho c_{p} \int_{Z 26}^{0}(T-26) d z,
$$

where $T, c_{p}$ and $\rho$ corresponds to the temperature, specific heat $\left(\mathrm{J} \mathrm{kg}^{-1}{ }^{\circ} \mathrm{C}^{-1}\right)$ capacity of seawater at constant pressure and density $\left(\mathrm{kg} / \mathrm{m}^{3}\right)$ respectively.

\section{3 | RESULTS}

Figure 1 shows the study domain as well as the occurrence of TC intensification over the $\mathrm{BoB}$ basin and its corresponding TCHP (Equation 2) and BLT (Equation 1). The data period 2003-2016 as available from the INCOIS-GODAS. It is noted that the TC intensification frequently occurs in a latitudinal band/range of about $\pm 3^{\circ}$ centred at $12^{\circ} \mathrm{N}$ with $7-11 \%$ frequency (Figure 1b). Likewise, the secondary intensification maxima occur in the latitudinal band of $15^{\circ} \mathrm{N}-22^{\circ} \mathrm{N}$ with a frequency of $4-5 \%$. No TC intensification is found in the near-equatorial region $\left(<5^{\circ} \mathrm{N} / \mathrm{S}\right)$ owing to the weak Coriolis force (Gray, 1968; Sikka, 1977). Importantly, the frequency of TC intensification occurrence is more in the longitudinal range of $80^{\circ} \mathrm{E}-90^{\circ} \mathrm{E}$ (Figure 1c). Thus, the overall results indicate that the central $\mathrm{BoB}$ experiences or is more prone to TC intensification as compared to the northern and southern BoB.

Figure 1d,e show the frequency distribution of TCHP and BLT corresponding to the locations of TC intensification shown in Figure 1b,c. From Figure 1d, the TC intensification occurrence is found to be highly correlated with the increase in TCHP (50-80 $\left.\mathrm{kJ} / \mathrm{cm}^{2}\right)$ indicating that high TCHP values are favourable for TC intensification. It is also noted that TCHP $>100 \mathrm{~kJ} / \mathrm{cm}^{2}$ is less frequent during the TC intensification stages. A study by Yan et al. (2017) also obtained a similar monotonic relation between TC intensification and TCHP over the Pacific Ocean. Moderate BLT $(\sim 10-30 \mathrm{~m})$ is more frequent during the TC evolution (Figure 1e). However, the frequency percentage of the BLT $(\sim 0-10 \mathrm{~m})$ corresponding to the TC intensification occurrence is less and could be due to the weak stratification which does not aid TC intensification and could lead to eventual weakening (Balaguru et al., 2012). Overall, analyses reveal that high TCHP $\left(\sim 50-80 \mathrm{~kJ} / \mathrm{cm}^{2}\right)$ and moderate BLT $(\sim 10-30 \mathrm{~m})$ favour TC intensification. This finding is also supported by the results reported in Balaguru et al. (2012) and Vissa et al. (2013b).

The azimuthally averaged TCHP within $400 \mathrm{~km}$ radial distance in the life cycle of the TC is shown in Figure 2. The intensifying (decaying) phase of $\mathrm{TC}$ at a particular time is measured based on the decrease (increase) in the central mean-sea-level pressure for the next two available data periods (i.e. 6 and $12 \mathrm{~h}$ ). The analyses show that the 

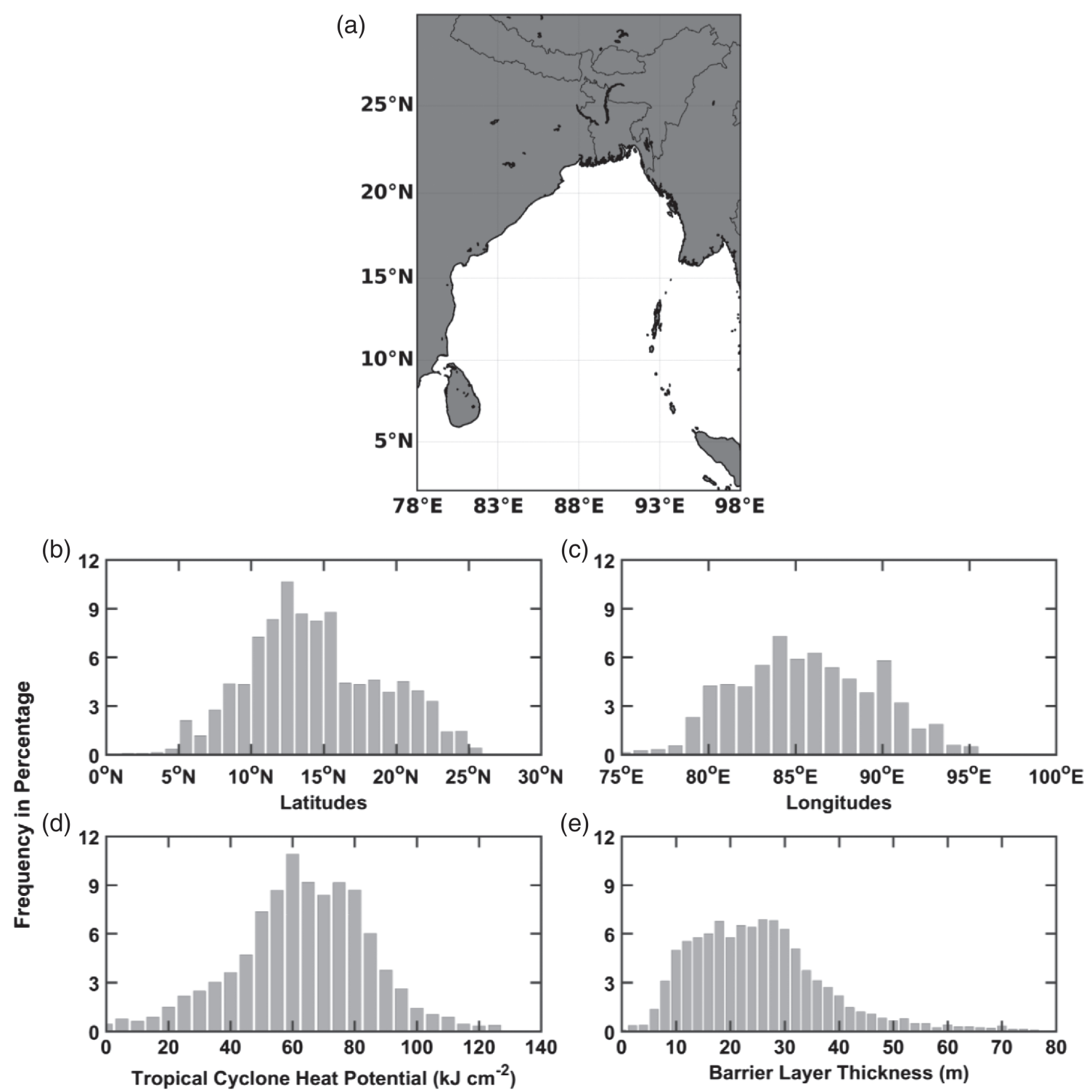

(e)

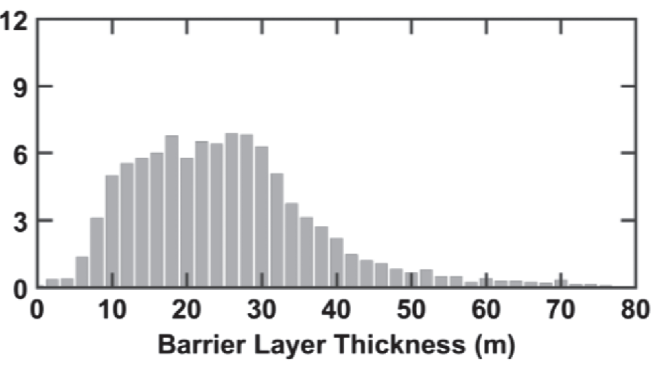

F I G URE 1 (a) The study region. The frequency percentage of TC intensification locations obtained from IMD best estimates as a function of (b) latitude, (c) longitude, over the BoB. (d,e) The percentage frequency of TCHP $\left(\mathrm{kJ} / \mathrm{cm}^{2}\right)$ and BLT (m) at the corresponding TC intensification locations shown in $(b, c)$

TCHP increases consistently up to $\sim 58-70 \mathrm{~kJ} / \mathrm{cm}^{2}$ during the intensification phase from DD to SCS stage and then decreases progressively to $\sim 65-60 \mathrm{~kJ} / \mathrm{cm}^{2}$ in the latter stages. These results are consistent with the findings reported in Malan et al. (2013)) and Oropeza and Raga (2015). The reduced TCHP variations during these stages are mainly due to the presence of strong winds from the SCS stage and higher categories, which results in surface cooling through turbulent vertical mixing processes (Emanuel, 2001; Sengupta et al., 2008; Balaguru et al., 2012; Mawren and Reason, 2017). Analysis of the decaying phase shows distinct signals (as those of the intensifying phase) illustrating a gradual decrease in the magnitude of TCHP for all the stages. This analysis is extended to understand the linear relation of BLT and TCHP concerning the TC intensity. The average value of TCHP and BLT corresponding to different wind speeds (intensity) is presented in Figure 2b. The BLT and TCHP parameters show decreasing behaviour with an increase in TC intensity. Multivariate regression analysis is developed (Intensity $=a^{*} \mathrm{BLT}+b^{*} \mathrm{TCHP}+c$ ) to estimate the combined effect of TCHP and BLT on TC intensity over the BoB. The TC samples from the period of 2003-2013 are used to develop the multivariate regression analysis and the remaining samples (2014-2016) are used for verification. The estimated regression coefficients for the TC intensification are $a=-0.04$, $b=0.09$ and $c=34.1$, although the $95 \%$ confidence intervals of these coefficients are $\pm 0.09, \pm 0.12$ and \pm 9.1 respectively. The regression analysis is performed against the observed TC intensity, and results are shown as a scatterplot (Figure 3). The analysis shows that the multivariate linear regression can estimate the observed intensity values up to the SCS stage in a reasonable manner with an RMSE of 11 knots and a bias of 

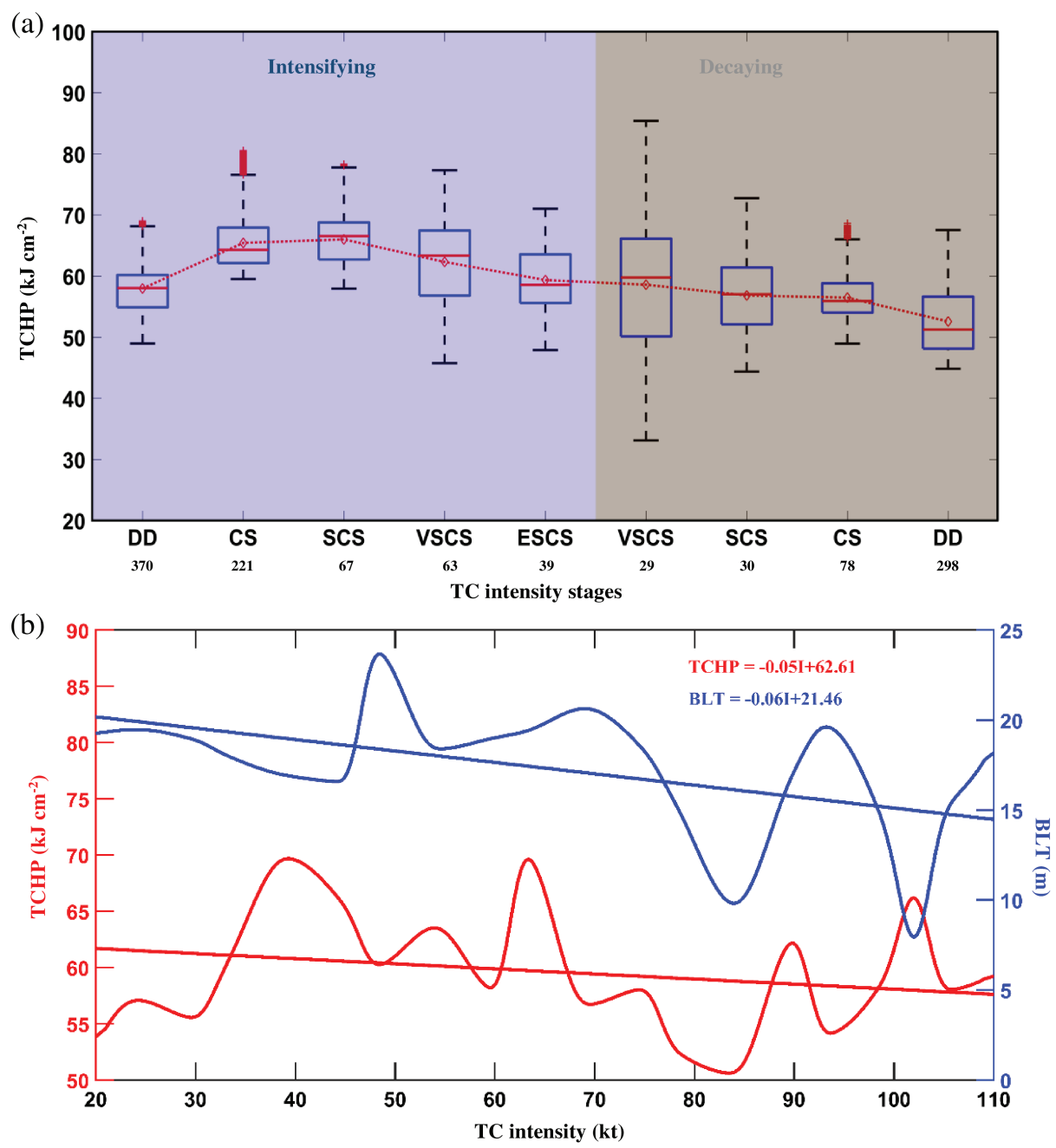

F I G U RE 2 (a) Statistical representation of TCHP $\left(\mathrm{kJ} / \mathrm{cm}^{2}\right)$ variability during TC life cycle, separating the intensifying stage (blue shade) and decaying stage (grey shade). (b) TC intensity (knots) relation with respect to TCHP and BLT. The thick red line and the dotted line in (a) represent the median and mean of the TCHP respectively. The number at each TC intensity category along $x$-axis in (a) is the number of samples. The red plus sign represents the outliers (data points that are extended out of the lower and upper extremes) [Colour figure can be viewed at wileyonlinelibrary.com]

7.24 knots. Conversely, the regression notably underestimates the stronger TCs (VSCS and above intensity stages) with an RMSE and a bias of 50 knots and 48 knots.

\section{1 | TCHPA composite structures}

The changes in TCHP primarily depend on factors such as the TC intensity (Shay et al., 2000; Knaff et al., 2013; Yan et al., 2017), translational speed (Lin et al., 2009b; Mei et al., 2012; Vincent et al., 2012), and seasonality (Krishnamurti et al., 2017; Busireddy et al., 2018). Therefore, additional analyses are carried out with respect to the season of formation, intensity, and translation speed. To understand the uncertainties in the TCHP anomaly (TCHPA) structures, a preliminary analysis is conducted to assess the role of different time lags of TCHPA in the TC evolution. In this context, the TCHPA product is prepared with respect to climatology, 5 days prior and 10 days before the formation of each cyclone. Figure 4a,b show the area average of TCHPA during the pre- and post-monsoon season for each TC intensity up to $400 \mathrm{~km}$ storm radius. The analysis shows significant differences between the pre- and post-monsoon seasons for the different time lags. The magnitude of peak negative TCHPA associated with the pre-monsoon TCs is $\sim 14, \sim 12.5$, $\sim 12.8 \mathrm{~kJ} / \mathrm{cm}^{2}$ respectively for the 5-day, 10-day and climatology products. Note that the negative TCHPA gradually increases from CS to VSCS stage and then decreases during the ESCS stage for all the products in the pre-monsoon period. Likewise, the post-monsoon TCs-induced changes of negative TCHPA are limited to $\sim 12, \sim 9.5$ and $\sim 8 \mathrm{~kJ} / \mathrm{cm}^{2}$ respectively for the 5-day, 10-day and climatology. These results indicate that the observed changes in TCHPA are prominent as the systems evolve from CS to ESCS stages. For example, ESCS shows the lowest change in TCHPA values compared to the other stages in the pre-monsoon period, while ESCS indicates the greatest change in TCHPA values during the post-monsoon season. The overall analysis depicts that the 
increases in the direction of TC movement as the TC inten-

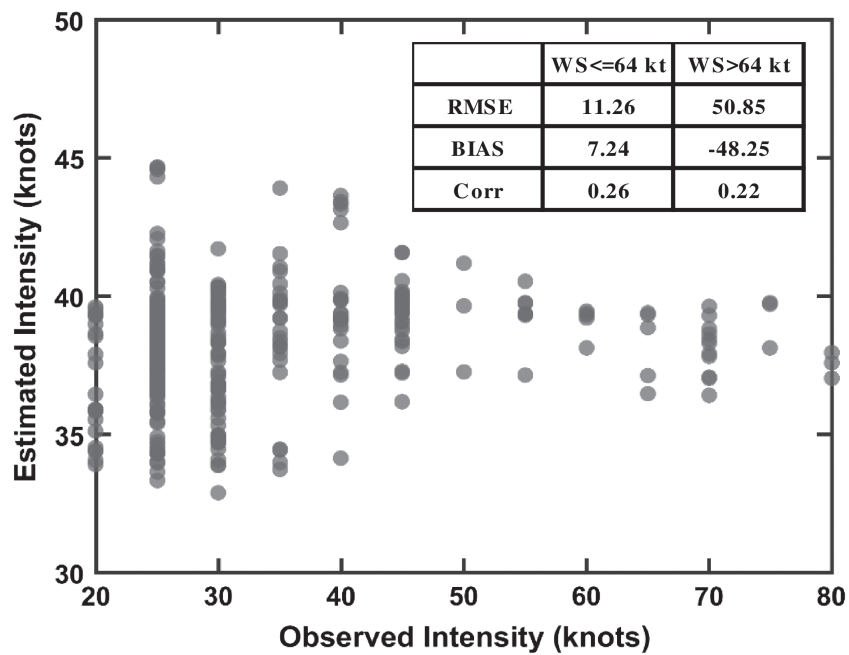

F I G U R E 3 Verification of multivariate regression for the period 2014-2017. Scatter diagram of observed and estimated intensity (knots) of TC samples during 2014-2017. Statistics for different intensity categories are shown in the table

TCHPA 5-day product shows strong variations in TCHPA as compared to the others during both the seasons (Figure 4a,b). Therefore, based on the above results, this study considers the 5-day TCHPA product suitable for analysis purposes, instead of the 10-day and climatology products.

Figure $4 \mathrm{c}-\mathrm{j}$ depict the composite structures of TCHPA for different TC intensity stages during pre- and post-monsoon seasons. The TC-induced TCHPA structures exhibit significant differences across the TC seasons. In the pre-monsoon season, the negative TCHPA (also referred to as cooling) is prominent in the TC rear sector for any intensity stage (Figure 4c-f). However, positive anomalies (i.e. warming) appear in the TC outer environment $(\sim 200-400 \mathrm{~km})$, particularly in TC forward sectors. Further, analysis indicates that as the TC intensity increases, the change in TCHPA also becomes more negative. During the early stage (CS), the change in TCHPA varies between -15 and $-20 \mathrm{~kJ} / \mathrm{cm}^{2}$ in the rear sector. As the system progresses to SCS stage, the change in TCHPA varies between -20 and $-25 \mathrm{~kJ} / \mathrm{cm}^{2}$ and further decreases up to $-30 \mathrm{~kJ} / \mathrm{cm}^{2}$ during the VSCS stage during pre-monsoon (Figure $4 \mathrm{c}-\mathrm{e}$ ). The strong negative anomalies observed in the rear sector could be related to the TCs that are formed during this season easily breaking the shallow $\mathrm{BL}$ and producing cold wakes along several hundred kilometres away from the TC track (Sengupta et al., 2008; Vissa et al., 2013b). Unlike during other intensity stages, the TCHPA structures at the ESCS stage are not significant due to fewer (7) samples (Figure 4d).

A similar analysis is conducted for the post-monsoon season and is shown in Figure 4g-j. Likewise, post-monsoon TCs also exhibits negative TCHPA (cooling) in the rear sector but this cooling is off along the TC track in all the intensity stages. Note that the magnitude of negative TCHPA and its spread sity increases. For instance, the observed negative anomalies corresponding to the CS, SCS, VSCS and ESCS stages are, respectively, $5-10 \mathrm{~kJ} / \mathrm{cm}^{2}, 10-15 \mathrm{~kJ} / \mathrm{cm}^{2}, 15-20 \mathrm{~kJ} / \mathrm{cm}^{2}$ and $20-25 \mathrm{~kJ} / \mathrm{cm}^{2}$ (Figure $4 \mathrm{~g}-\mathrm{j}$ ). The TC-induced negative TCHPA is stronger in the pre-monsoon season as compared to the post-monsoon. The mean negative TCHPAs for the pre- and the post-monsoon seasons are 8 and $6 \mathrm{~kJ} / \mathrm{cm}^{2}$. Furthermore, the peak cooling (negative TCHPA) of $>25 \mathrm{~kJ} / \mathrm{cm}^{2}$ is evident in both the SCS and VSCS stages during the pre-monsoon season, whereas it is limited to $20-25 \mathrm{~kJ} / \mathrm{cm}^{2}$ at the ESCS stage of the post-monsoon season. This is likely due to the formation of thick BL due to the large river discharge and higher precipitation during the summer monsoon season over the BoB (Neetu et al., 2012; Prakash and Pant, 2017).

The azimuthally averaged radial and spatial distribution (up to $400 \mathrm{~km}$ ) of negative TCHPA as a function of slow, normal and fast movers is shown in Figure 5. The analysis clearly shows the increase in negative TCHPA for the slow movers followed by the normal and fast movers up to $\sim 300 \mathrm{~km}$ radial distance from the storm centre. The magnitude of peak negative TCHPA is $\sim 12, \sim 7.5$ and $\sim 3 \mathrm{~kJ} / \mathrm{cm}^{2}$ for the slow, normal and fast movers, respectively, in the inner-core $(0-100 \mathrm{~km})$ region. Beyond $100 \mathrm{~km}$, the negative TCHPA tended to decrease over radial distance for all the TC translation speeds and became nearly constant around $\sim 370-400 \mathrm{~km}$ (Figure 5a). It infers that TC impact or influence is limited up to $400 \mathrm{~km}$ radius in the $\mathrm{BoB}$ region. The higher negative TCHPA during the slow movers could be attributed to (a) stronger TC intensity as shown in Figure 5b, and (b) vigorous turbulent mixing favoured by vertical current shear (Sengupta et al., 2008; Vissa et al., 2013b). Figure 5b shows the mean TC intensity estimated for the slow, normal, and fast movers in terms of $10 \mathrm{~m}$ maximum sustained winds. The observed mean intensities of the slow, normal and fast movers are $\sim 34$ knots, $~ 31$ knots and $\sim 29$ knots, respectively (Figure $5 b$ ). The range of intensities varies for the slow, normal and fast movers as $\sim 20-55$ knots, $\sim 20-52$ knots and $\sim 20-36$ knots. These analyses reinforce that TC intensity decreases with an increase in translation speed. The overall results highlight that the slower movers are relatively stronger as compared to normal and fast movers and peak negative TCHPA is in the TC rear sectors.

From the above analysis, it is obvious that the slow-moving TC-induced negative TCHPA is more as compared to the normal and fast movers (Figure 5c-e). The distributed peak negative TCHPA of $>15 \mathrm{~kJ} / \mathrm{cm}^{2}$ is seen up to $\sim 300 \mathrm{~km}$ storm radius in the TC rear sector (Mei et al., 2012). The negative TCHPA values of $\sim 10-15 \mathrm{~kJ} / \mathrm{cm}^{2}$ are observed for the normal movers, particularly along the track direction up to $400 \mathrm{~km}$ radius in the rear sector (Figure 5d). Dare and McBride (2011) also reported the maximum cooling in the wake to the TC rear sector and along the track. As regards 
(a)

Pre-monsoon

TC intensity stages

(b) Post-monsoon
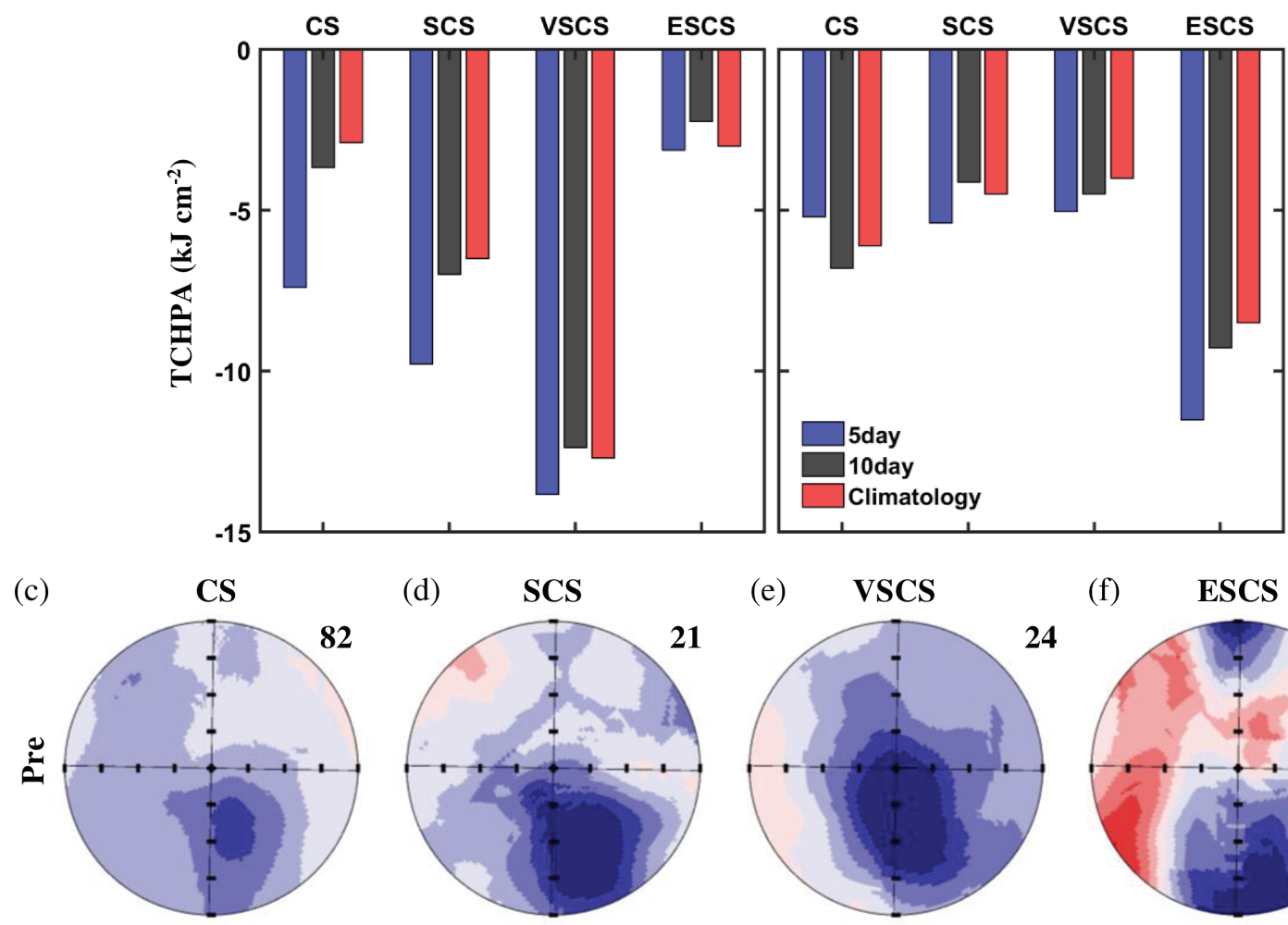

(e)

(f)

$\mathbf{k J ~ \mathbf { ~ c m } ^ { - 2 }}$

$(\mathrm{g})$

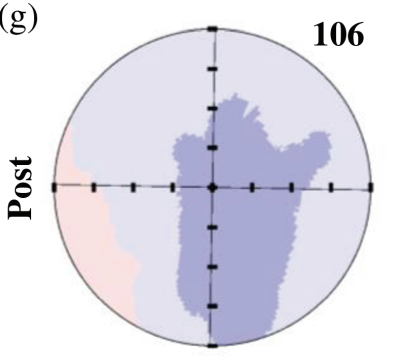

(h)

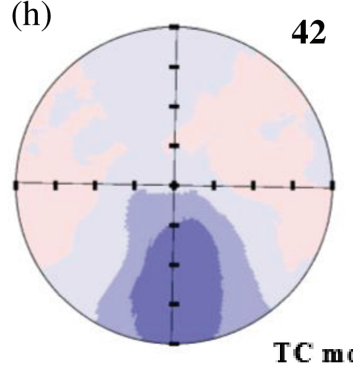

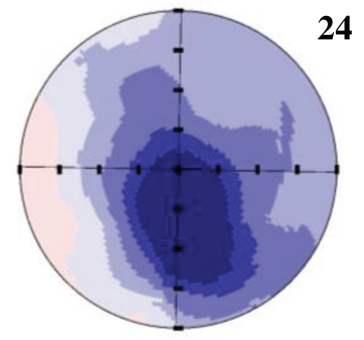

(i)

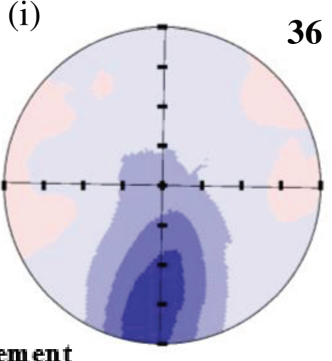

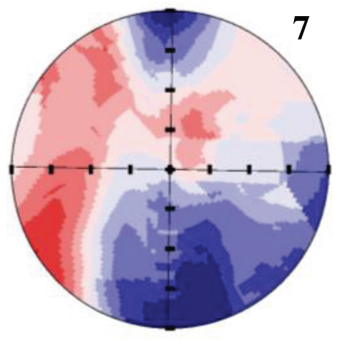

(j)

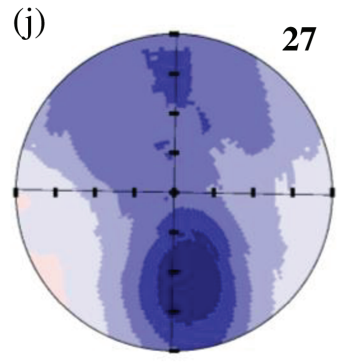

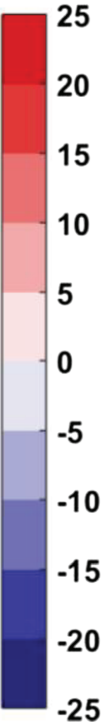

(k)

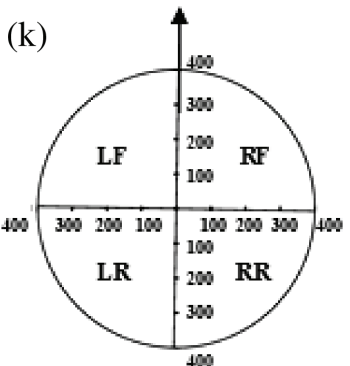

F I G U R E 4 TCHPA changes with respect to the different time lags of (a) pre- and (b) post-monsoon seasons. Spatial structures of TCHPA at different TC intensity categories: (c) CS, (d) SCS, (e) VSCS, and (f) ESCS for the pre-monsoon season, and (g-j) as (c-f) but for post-monsoon season. (k) The schematic representation of the storm centre to the $400 \mathrm{~km}$ radius. Each tick mark around the storm centre represents $100 \mathrm{~km}$ distance. Up-arrow represents the TC movement; and LF, RF, LR and RR indicates the left-front, right-front, left-rear and right-rear sectors of the TC [Colour figure can be viewed at wileyonlinelibrary.com]

the fast movers, the low negative TCHPA $\left(\sim 5-10 \mathrm{~kJ} / \mathrm{cm}^{2}\right)$ values are found beyond $100 \mathrm{~km}$ up to $400 \mathrm{~km}$ radius in the rear sector (Figure 5e). It could be due to the short residence time of the fast movers at a given location (Mei et al., 2012). The overall analyses revealed that as the translation speed increases (slow, normal and fast), the corresponding TC intensities and negative TCHPA decrease.

\subsection{Relation between BLT and TCHP during intensification phase}

In Figure 6, the grid-wise average of all the TC samples related to the BLT, D26 (depth of $26^{\circ} \mathrm{C}$ isotherm), TCHP and TCHPA is estimated separately for pre- and post-monsoon seasons in the inner core region $(0-100 \mathrm{~km})$. The present 

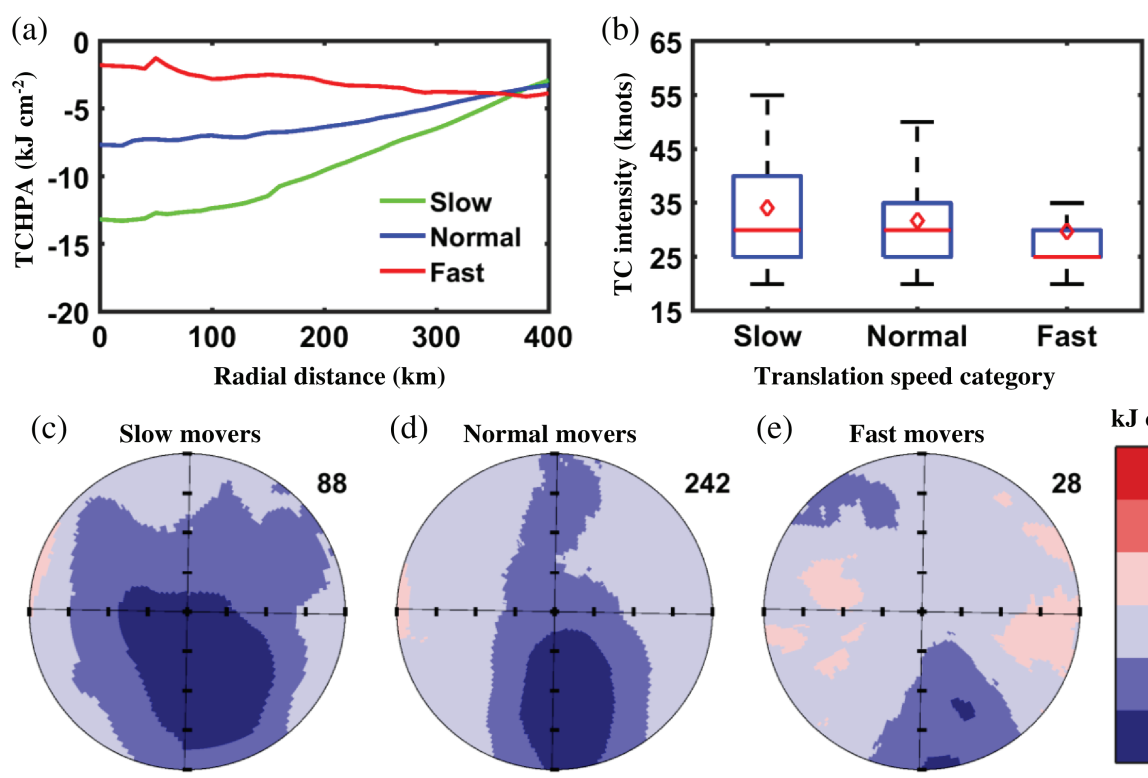

(d) Normal movers
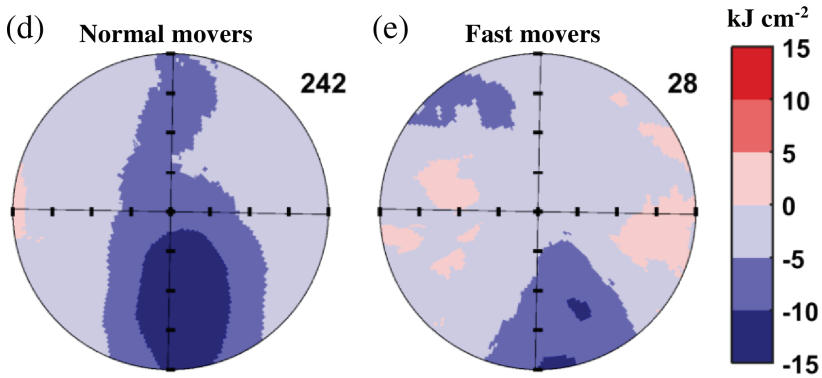

F I G U R E 5 TC-induced changes in TCHPA as a function of TC translation speed. (a) Azimuthally averaged TCHPA up to $400 \mathrm{~km}$ storm radius. (b) Average intensities of slow, normal and fast-moving TCs. Spatial distribution of TCHPA structures of (c) slow, (d) normal, and (e) fast-moving TCs. The numbers in (c-e) represent the number of samples used in the analyses and the red symbol and red line in (b) indicate the average TC intensity and median respectively [Colour figure can be viewed at wileyonlinelibrary.com]

analysis seeks to understand the one-to-one correspondence between these parameters during the pre- and post-monsoon in the intensifying phase of a TC. Note that the TC samples belonging to the decaying phase are not included because of their interaction with the coast and insufficient coastal observations in the model analyses. The analysis in Figure 6a shows that the observed TCHP is larger during the pre-monsoon season $\left(\sim 77-100 \mathrm{~kJ} / \mathrm{cm}^{2}\right)$ than that in the post-monsoon season $\left(\sim 50-72 \mathrm{~kJ} / \mathrm{cm}^{2}\right)$. These high TCHP values during the pre-monsoon season may be attributed to the strong insolation and cloud-free skies (Vissa et al., 2013a; Weller et al., 2016). Contrastingly, the BLT is smaller during the pre-monsoon $(\sim 12-17 \mathrm{~m})$ as compared to the post-monsoon season $(\sim 22-33 \mathrm{~m})$, owing to the large cooling (in terms of negative TCHPA) in the pre-monsoon season (refer to Figure $4 \mathrm{c}-\mathrm{f})$. These results are consistent with earlier studies (Sengupta et al., 2008; Vissa et al., 2013c).

Statistical analyses further show a positive correlation $(r=0.75)$ between BLT and TCHP in TC seasons (i.e. mean of pre- and post-monsoon). However, if the individual seasons are concerned, the relation is opposite in a manner showing a strong positive correlation $(\mathrm{r}=0.92)$ during post-monsoon and weak negative correlation $(\mathrm{r}=-0.40)$ in the pre-monsoon season. These distinct relations found during these seasons are primarily due to the seasonal variations of stratification in the BoB region. As mentioned, the post-monsoon (pre-monsoon) season is characterized by strong (weak) stratification with thick (thin) barrier layers. Moreover, the cyclonic winds erode the thin BL and directly interact with the thermocline waters, resulting in large changes in TCHP values (Sengupta et al., 2008).
The analyses indicate the BLT and TCHP relation varies with season. The TCHP is derived from the depth of D26, so they might exhibit a positive relation with each other in all the seasons. Here, the same one-to-one correspondence between D26 and the TCHPA in the presence of TCs is analysed during the pre-, post-monsoon and entire TC seasons (Figure 6b). The analysis shows that the negative TCHPA (i.e. cooling) is more if D26 is shallower; and, the deeper the D26, the less the cooling. However, the rate of cooling is different across the seasons. During the pre-monsoon season, D26 varies between $\sim 73$ and $83 \mathrm{~m}$ and the corresponding cooling is $\sim 15 \mathrm{~kJ} / \mathrm{cm}^{2}$, whereas, for the post-monsoon season, the cooling associated with the D26 ranging between 58 and $70 \mathrm{~m}$ is $9 \mathrm{~kJ} / \mathrm{cm}^{2}$. This analysis highlights the significance of TCHPA cooling to the depth of D26.

\section{3 $\mid$ Structure of SST anomaly}

The SST influences, and is influenced by, the TC intensity and its translation speed (Lin et al., 2009a,b; Pothapakula et al., 2017). Figure 7a,b show the semi-log plot of azimuthally averaged radial profile of surface cooling (represented by negative SST anomaly or SSTA) up to $400 \mathrm{~km}$ from TC centre with different translation speeds and intensity categories. It is obvious that slow-moving TCs produce a greater cooling response than that of normal and fast movers (Figure 7a). The mean SSTA values corresponding to the slow, normal and fast movers are $\sim 0.5, \sim 0.35$ and $\sim 0.12{ }^{\circ} \mathrm{C}$ respectively, in the inner-core region (Figure $7 \mathrm{a}$ ). From Figure $7 b$, it is realized that the TC-induced cooling is high at the VSCS stage followed by SCS and CS stages; the corresponding 

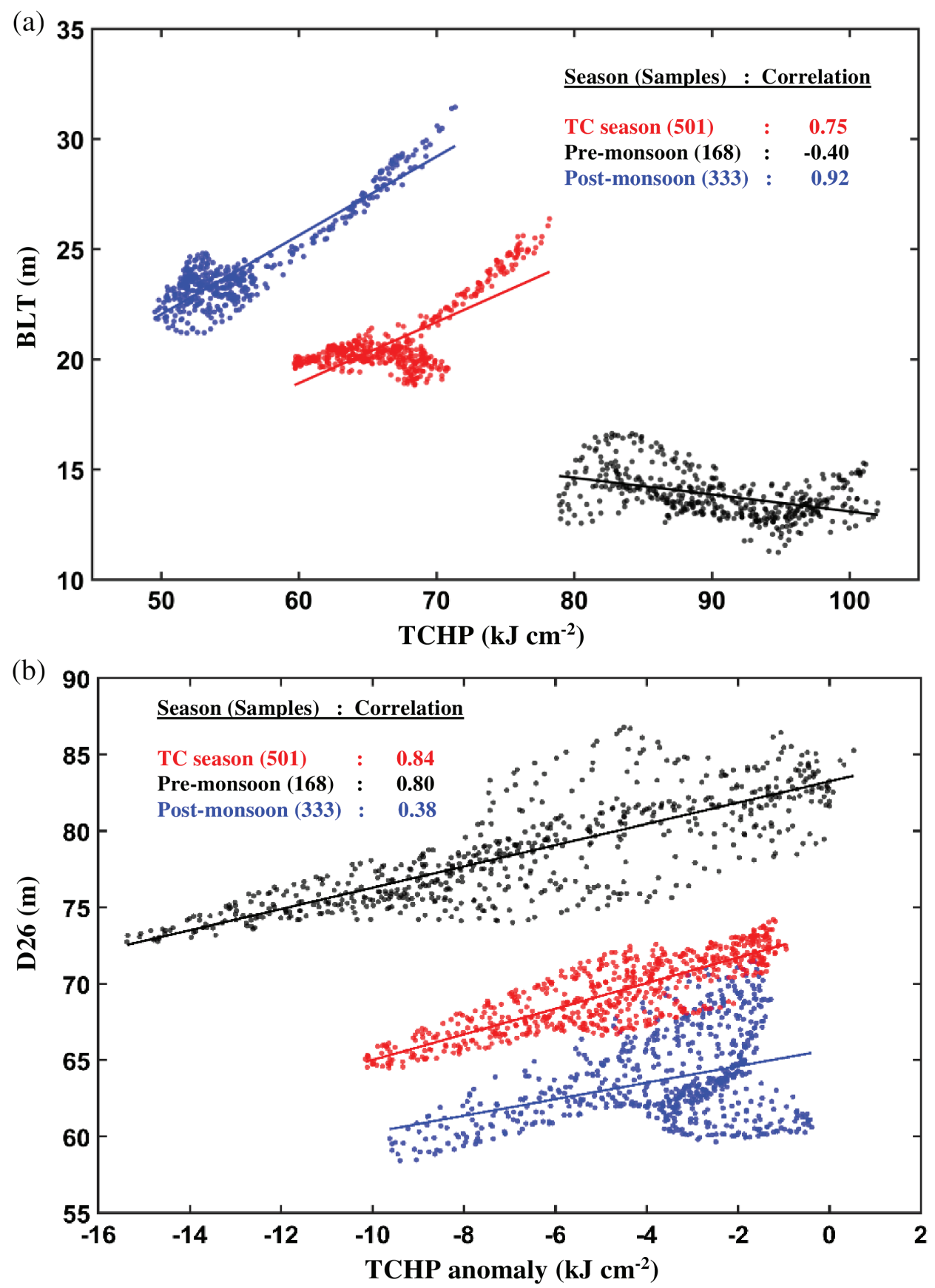

F I G U R E 6 Statistical relation between (a) TCHP $\left(\mathrm{kJ} / \mathrm{cm}^{2}\right)$ and BLT (m), and (b) TCHPA with D26 (m) during pre-monsoon, post-monsoon and the TC seasons [Colour figure can be viewed at wileyonlinelibrary.com]

values are $>0.7,<0.5$ and $<0.37{ }^{\circ} \mathrm{C}$ respectively in the TC inner-core region (Pothapakula et al., 2017). Note that the ESCS stage analysis is not included in this study due to the limited samples.

Figure $7 \mathrm{c}$ investigates the mean influence of TC intensity and translation speed on SST cooling patterns within the TC core region. Overall analyses indicate that when a TC is at the DD or CS stage, the mean induced cooling is $\sim 0.2-0.5^{\circ} \mathrm{C}$ for any translation speed (except for fast-moving TCs with $8-10 \mathrm{~m} / \mathrm{s}$ ). As the TC intensity increases (SCS and above), there is a large difference in the SST cooling values for different translation speeds. For instance, the TC-induced cooling ranges between $\sim 0.8$ and $1.2^{\circ} \mathrm{C}$, when a TC is located at the SCS strength for any translation speeds up to $10 \mathrm{~m} / \mathrm{s}$. This kind of similar surface cooling feature is seen in the VSCS and ESCS stages also. The large cooling is statistically significant and could be attributed to the intense vertical mixing, transient upwelling and heavy rainfall in the TC core region (Emanuel, 2001; Trenberth and Fasullo, 2007). However, the intense TCs (SCS and greater strength) moving with more than $10 \mathrm{~m} / \mathrm{s}$ translation speeds induce significantly less cooling. The reason behind the weaker SST cooling in the fast 

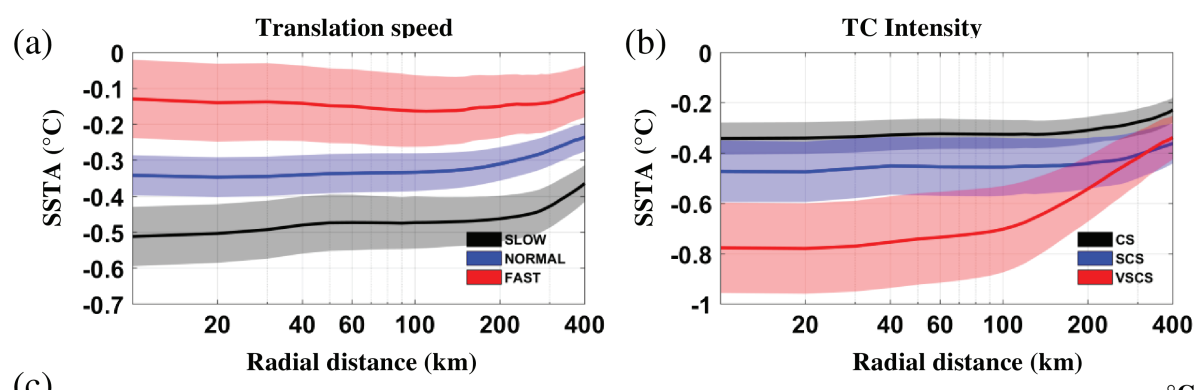

(c)

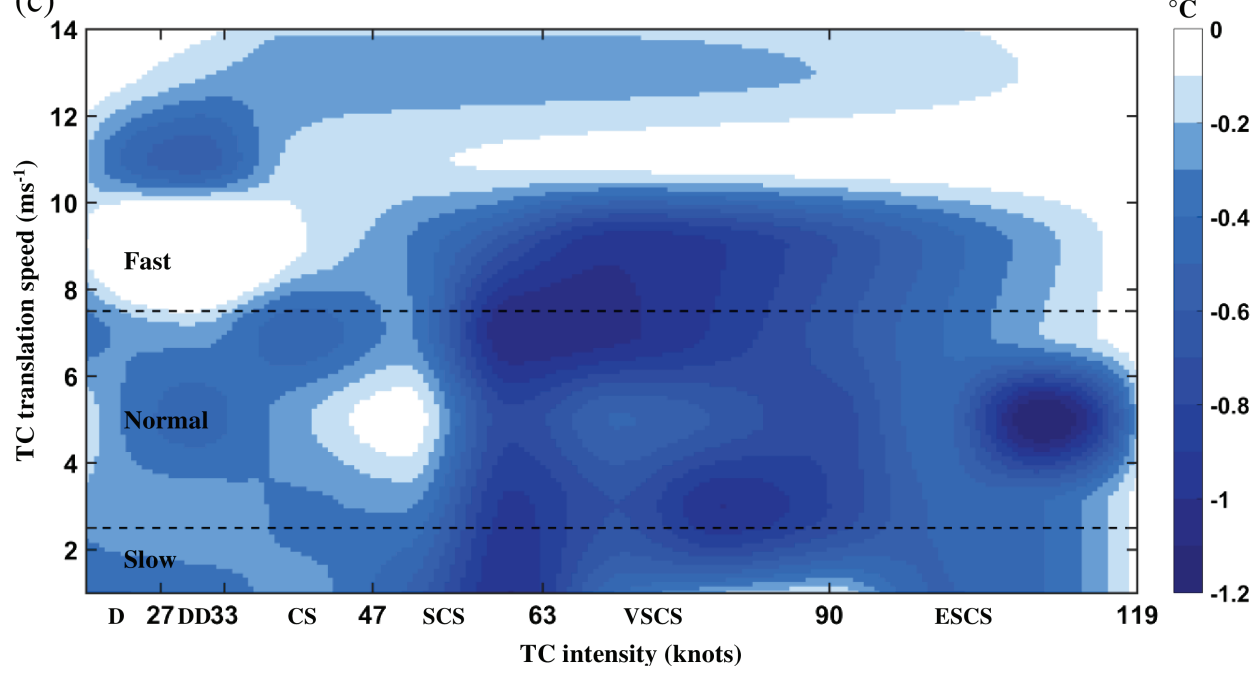

F I G U R E 7 Radial profiles of azimuthally averaged SSTA $\left({ }^{\circ} \mathrm{C}\right)$ with respect to (a) translation speed (m/s), and (b) TC intensity category from TC centre to $400 \mathrm{~km}$ radial distance. The shading in (a,b) represents the $99 \%$ confidence interval. (c) The combined effect of TC translation speed and intensity on SSTA. The dashed lines indicate threshold value for slow, normal and fast-moving TCs [Colour figure can be viewed at wileyonlinelibrary.com]

movers $(>10 \mathrm{~m} / \mathrm{s})$ is the short exposure time over the ocean (Mei et al., 2012).

Figure 8 shows the probability density function (PDF) of azimuthally averaged SSTA within $100 \mathrm{~km}$ storm radius as a function of TC season and translation speed. The analysis shows cooling range from 0.37 to $0.56{ }^{\circ} \mathrm{C}$ with a single mode of maximum centred at $\sim 0.45{ }^{\circ} \mathrm{C}$ at $25 \%$ frequency for the pre-monsoon TCs (Figure 8a). This cooling can be attributed to the presence of a shallow BL in the pre-monsoon season (Figure 6a). Contrastingly, the computed SSTA during the post-monsoon season shows less variability, with two significant modes. The primary (secondary) maximum cooling of $\sim 0.33{ }^{\circ} \mathrm{C}\left(\sim 0.28{ }^{\circ} \mathrm{C}\right)$ is more (less) frequent at $\sim 25 \%$ $(\sim 12 \%)$. The observed smaller range of maximum cooling spread in the post-monsoon season could be attributed to the presence of thermal inversions and salinity-stratified thick BL (Neetu et al., 2012; Pothapakula et al., 2017; Prakash and Pant, 2017). A similar kind of PDF analysis constructed for the TCs moving with different translation speeds is presented in Figure 8b. The analysis associated with the slow movers shows that the values range from 0.4 to $0.6{ }^{\circ} \mathrm{C}$ with a primary maximum of $\sim 0.53{ }^{\circ} \mathrm{C}$ at $23 \%$ frequency and a secondary maximum of $\sim 0.42{ }^{\circ} \mathrm{C}$ at $12 \%$. Likewise, the normal (fast) movers exhibit a cooling of $\sim 0.35{ }^{\circ} \mathrm{C}\left(\sim 0.12{ }^{\circ} \mathrm{C}\right)$ at $\sim 32 \%$ ( $\sim 27 \%$ ) frequency. The overall results concluded that a slow-moving TC during the pre-monsoon season produces or causes larger surface cooling over the BoB.

\section{SUMMARY AND CONCLUSION}

The TC influence on the spatial structure/pattern of ocean parameters (TCHPA, BLT, SSTA) up to $400 \mathrm{~km}$ radial distance from the TC centre is studied using INCOIS-GODAS analysis over the BoB. This analysis is carried out based on 1,222 individual samples collected from 83 TCs during the 2003-2016 period. The response of ocean parameters to TCs are for the season of formation, the intensity of the TC (CS, SCS and VSCS) and translation speed (slow, normal and fast). The salient features of this study are summarized below.

The results revealed that the occurrence of TC intensification is more evident over the central $\mathrm{BoB}$ as compared to the north and southern BoB; and both BLT and TCHP favour TC intensification. The spatial structures of TCHPA revealed that strong negative anomaly is observed in the TC rear sector (for any season and translation speed). The increase in negative TCHPA with the intensity from CS to VSCS stages ranges from $\sim 10-15 \mathrm{~kJ} / \mathrm{cm}^{2}$ to $\sim 25-30 \mathrm{~kJ} / \mathrm{cm}^{2}$ respectively. The slow movers produce strong negative TCHPA as compared to that of normal and fast movers. As the TC translation 
(a)

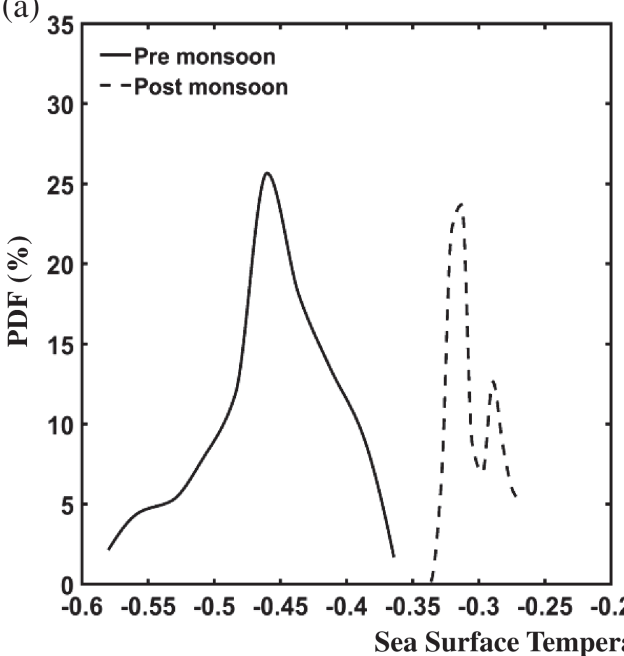

(b)

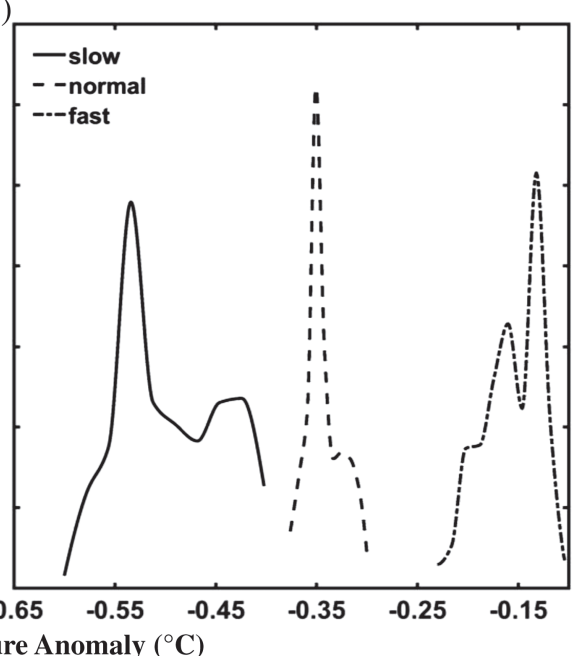

F I G U R E 8 Probability density function (PDFs) of SSTA $\left({ }^{\circ} \mathrm{C}\right)$ for (a) TC seasons, and (b) translation speeds of TCs

speed increases, the location of maximum negative TCHPA is shifted from the TC centre to further away and aligned with the TC track. The azimuthally averaged TCHP analyses indicated that the ocean thermal energy plays an important role in the intensification process (i.e. up to SCS stage). The higher TCHP dominates during the pre-monsoon season while both high TCHP and deep BLT prevails during the post-monsoon season.

The surface cooling patterns of SSTA show distinct changes in the slow movers followed by the normal and fast movers in the TC core region. The SST cooling slowly reduces with an increase in the radial distance. The maximum negative cooling of $\sim 0.8-1.2{ }^{\circ} \mathrm{C}$ is found for the SCS strength and above categories when the translation speed is below $10 \mathrm{~m} / \mathrm{s}$. The PDFs of SSTA in the TC core region for the preand post-monsoon seasons show maximum cooling of $\sim 0.45$ and $\sim 0.33{ }^{\circ} \mathrm{C}$ is more frequent at $\sim 25 \%$. Similar PDFs of maximum cooling for the slow, normal and fast movers are $\sim 0.53, \sim 0.35$ and $\sim 0.12{ }^{\circ} \mathrm{C}$ with a frequency of $\sim 23, \sim 32$ and $27 \%$. Overall results emphasize that stronger, slow movers and pre-monsoon season TCs exhibit prominent cooling over the BoB.

\section{ACKNOWLEDGEMENTS}

The authors gratefully acknowledge the financial support (ECR/2016/001637) of SERB, Department of Science and Technology (DST), Govt. of India, Earth System Science Organization, Ministry of Earth Sciences (MoES/16/14/2014-RDEAS), Govt. of India. The authors also acknowledge the SERB-Purdue OVDF programme (SB/S9/Z-03/2017) for partial support. DN acknowledges the U.S. NSF grants: OAC-1835739, AGS-1522494, and USDA Hatch Project at Purdue University. The authors thank the INCOIS, Hyderabad for providing the GODAS product through the website.

\section{OR CID}

Kumar Ankur (10) https://orcid.org/0000-0002-6243-7094

Krishna Kishore Osuri (10) https://orcid.org/0000-0001-

9088-9656

Sanikommu Sivareddy (1) https://orcid.org/0000-0001-8047481X

Dev Niyogi (D) https://orcid.org/0000-0002-1848-5080

\section{REFERENCES}

Ali, M.M., Sharma, R. and Cheney, R.E. (1998) An atlas of the north Indian Ocean eddies from TOPEX altimeter derived sea surface heights. Bangalore: Indian Space Research Organization, Special Report ISRO-SAC-SP-69-9, pp 6.

Balaguru, K., Chang, P., Saravanan, R., Leung, L.R., Xu, Z., Li, M. and Hsieh, J.S. (2012) Ocean barrier layers' effect on tropical cyclone intensification. Proceedings of the National Academy of Sciences of the USA, 109(36), 14343-14347.

Black, P.G. (1983) Ocean temperature changes induced by tropical cyclones. Ph.D. dissertation, University Park, PA: Pennsylvania State University, pp 278.

Busireddy, N.K.R., Osuri, K.K., Sivareddy, S. and Venkatesan, R. (2018) An observational analysis on the evolution of a mesoscale anti-cyclonic eddy over the Northern Bay of Bengal during May-July 2014. Ocean Dynamics, 68(11), 1431-1441. https://doi.org/10.1007/ s10236-018-1202-4.

Chan, J.C. and Gray, W.M. (1982) Tropical cyclone movement and surrounding flow relationships. Monthly Weather Review, 110, 1354-1374.

Dare, R.A. and McBride, J.L. (2011) Sea surface temperature response to tropical cyclones. Monthly Weather Review, 139(12), 3798-3808.

D'Asaro, E.A., Sanford, T.B., Niiler, P.P. and Terrill, E.J. (2007) Cold wake of hurricane Frances. Geophysical Research Letters, 34(15), 1-6. https://doi.org/10.1029/2007GL030160. 
Emanuel, K. (2001) Contribution of tropical cyclones to meridional heat transport by the oceans. Journal of Geophysical Research, 106(D14), 14771-14781.

Foltz, G.R. and McPhaden, M.J. (2009) Impact of barrier layer thickness on SST in the central tropical North Atlantic. Journal of Climate, 22(2), 285-299.

Fu, H.L., Wang, X., Chu, P.C., Zhang, X., Han, G. and Li, W. (2014) Tropical cyclone footprint in the ocean mixed layer observed by Argo in the northwest Pacific. Journal of Geophysical Research: Oceans, 119, 8078-8092. https://doi.org/10.1002/2014JC010316.

Goni, G.J. and Trinanes, J.A. (2003) Ocean thermal structure monitoring could aid in the intensity forecast of tropical cyclones. Eos Transactions American Geophysical Union, 84(51), 573-578.

Gray, W.M. (1968) Global view of the origin of tropical disturbances and storms. Monthly Weather Review, 96, 669-700.

India Meteorological Department. (2008) Tracks of Cyclones and Depressions in the Bay of Bengal and Arabian Sea 1891-2007. Electronic Version 1.0/2008. Chennai: IMD.

Knaff, J.A., DeMaria, M., Sampson, C.R., Peak, J.E., Cummings, J. and Schubert, W.H. (2013) Upper oceanic energy response to tropical cyclone passage. Journal of Climate, 26(8), 2631-2650.

Krishnamurti, T.N., Jana, S., Krishnamurti, R., Kumar, V., Deepa, R., Papa, F., Bourassa, M.A. and Ali, M.M. (2017) Monsoonal intraseasonal oscillations in the ocean heat content over the surface layers of the Bay of Bengal. Journal of Marine Systems, 167, 19-32.

Leipper, D.F. and Volgenau, D. (1972) Hurricane heat potential of the Gulf of Mexico. Journal of Physical Oceanography, 2(3), 218-224.

Li, Y., Han, W., Ravichandran, M., Wang, W., Shinoda, T. and Lee, T. (2017) Bay of Bengal salinity stratification and Indian summer monsoon intraseasonal oscillation: 1. Intraseasonal variability and causes. Journal of Geophysical Research: Oceans, 122(5), 4291-4311.

Lin, I.-I., Chen, C.-H., Pun, I.-F., Liu, W.T. and Wu, C.-C. (2009a) Warm ocean anomaly, air sea fluxes, and the rapid intensification of tropical cyclone Nargis (2008). Geophysical Research Letters, 36(3), 1-5. https://doi.org/10.1029/2008GL035815.

Lin, I.-I., Goni, G.J., Knaff, J.A., Forbes, C. and Ali, M.M. (2013) Ocean heat content for tropical cyclone intensity forecasting and its impact on storm surge. Natural Hazards, 66(3), 1481-1500.

Lin, I.-I., Pun, I.-F. and Wu, C.-C. (2009b) Upper-ocean thermal structure and the western North Pacific category 5 typhoons. Part II: Dependence on translation speed. Monthly Weather Review, 137(11), 3744-3757.

Lin, I.-I., Wu, C.-C., Pun, I.-F. and Ko, D.-S. (2008) Upper-ocean thermal structure and the western North Pacific category 5 typhoons. Part I: Ocean features and the category 5 typhoons' intensification. Monthly Weather Review, 136(9), 3288-3306.

Lonfat, M., Marks Jr, F.D.., and Chen, S.S. (2004) Precipitation distribution in tropical cyclones using the Tropical Rainfall Measuring Mission (TRMM) microwave imager: a global perspective. Monthly Weather Review, 132(7), 1645-1660.

Malan, N., Reason, C.J.C. and Loveday, B.R. (2013) Variability in tropical cyclone heat potential over the southwest Indian Ocean. Journal of Geophysical Research: Oceans, 118(12), 6734-6746.

Mawren, D. and Reason, C.J.C. (2017) Variability of upper-ocean characteristics and tropical cyclones in the south west Indian Ocean. Journal of Geophysical Research: Oceans, 122(3), 2012-2028.

McPhaden, M.J., Foltz, G.R., Lee, T., Murty, V.S.N., Ravichandran, M., Vecchi, G.A., Vialard, J., Wiggert, J.D. and Yu, L. (2009)
Ocean-atmosphere interactions during cyclone Nargis. Eos Transactions American Geophysical Union, 90(7), 53-54.

Mei, W., Pasquero, C. and Primeau, F. (2012) The effect of translation speed upon the intensity of tropical cyclones over the tropical ocean. Geophysical Research Letters, 39(7), 1-6. https://doi.org/10.1029/ 2011GL050765.

Mohapatra, M., Bandyopadhyay, B.K. and Nayak, D.P. (2013a) Evaluation of operational tropical cyclone intensity forecasts over north Indian Ocean issued by India Meteorological Department. Natural Hazards, 68(2), 433-445.

Mohapatra, M., Nayak, D.P., Sharma, R.P. and Bandyopadhyay, B.K. (2013b) Evaluation of official tropical cyclone track forecast over north Indian Ocean issued by India Meteorological Department. Journal of Earth System Science, 122(3), 589-601.

Neetu, S., Lengaigne, M., Vincent, E.M., Vialard, J., Madec, G., Samson, G., Ramesh Kumar, M.R. and Durand, F. (2012) Influence of upper-ocean stratification on tropical cyclone-induced surface cooling in the Bay of Bengal. Journal of Geophysical Research, 117(C12), 1-19. https://doi.org/10.1029/2012JC008433.

Oropeza, F. and Raga, G.B. (2015) Rapid deepening of tropical cyclones in the northeastern tropical Pacific: the relationship with oceanic eddies. Atmosfera, 28(1), 27-42.

Osuri, K.K., Mohanty, U.C., Routray, A., Mohapatra, M. and Niyogi, D. (2013) Real-time track prediction of tropical cyclones over the North Indian Ocean using the ARW model. Journal of Applied Meteorology and Climatology, 52(11), 2476-2492.

Pothapakula, P.K., Osuri, K.K., Pattanayak, S., Mohanty, U.C., Sil, S. and Nadimpalli, R. (2017) Observational perspective of SST changes during life cycle of tropical cyclones over Bay of Bengal. Natural Hazards, 88(3), 1769-1787.

Prakash, K.R. and Pant, V. (2017) Upper oceanic response to tropical cyclone Phailin in the Bay of Bengal using a coupled atmosphere-ocean model. Ocean Dynamics, 67(1), 51-64.

Ravichandran, M., Behringer, D., Sivareddy, S., Girishkumar, M.S., Chacko, N. and Harikumar, R. (2013) Evaluation of the global ocean data assimilation system at INCOIS: the tropical Indian Ocean. Ocean Modelling, 69, 123-135. https://doi.org/10.1016/j.oceamod. 2013.05.003.

Sadhuram, Y. (2004) Record decrease of sea surface temperature following the passage of a super-cyclone over the Bay of Bengal. Current Science, 86(3), 383-384.

Sengupta, D., Goddalehundi, B.R. and Anitha, D.S. (2008) Cyclone-induced mixing does not cool SST in the post-monsoon north Bay of Bengal. Atmospheric Science Letters, 9(1), 1-6.

Shay, L.K., Goni, G.J. and Black, P.G. (2000) Effects of a warm oceanic feature on Hurricane Opal. Monthly Weather Review, 128(5), 1366-1383.

Sikka, D.R. (1977) Some aspects of the life history, structure and movement of monsoon depressions. Pure and Applied Geophysics, 115, 1501-1529.

Sivareddy, S. (2015) A study on global ocean analysis from an ocean data assimilation system and its sensitivity to observations and forcing fields. Ph.D. thesis, Visakhapatnam: Department of Meteorology and Oceanography, Andhra University.

Sivareddy, S., Paul, A., Sluka, T., Ravichandran, M. and Kalnay, E. (2017) The pre-Argo ocean reanalyses may be seriously affected by the spatial coverage of moored buoys. Scientific Reports, 7, 46685.

Sprintall, J. and Tomczak, M. (1992) Evidence of the barrier layer in the surface layer of the Tropics. Journal of Geophysical Research, 97(C5), 7305-7316. 
Trenberth, K.E. and Fasullo, J. (2007) Water and energy budgets of hurricanes and implications for climate change. Journal of Geophysical Research, 112(D23), 1-10. https://doi.org/10.1029/2006JD008304.

Vincent, E.M., Lengaigne, M., Madec, G., Vialard, J., Samson, G., Jourdain, N.C., Menkes, C.E. and Jullien, S. (2012) Processes setting the characteristics of sea surface cooling induced by tropical cyclones. Journal of Geophysical Research, 117(C2), 1-18. https://doi.org/10. 1029/2011JC007396.

Vissa, N.K., Satyanarayana, A.N.V. and Kumar, B.P. (2013a) Intensity of tropical cyclones during pre-and post-monsoon seasons in relation to accumulated tropical cyclone heat potential over Bay of Bengal. Natural Hazards, 68(2), 351-371.

Vissa, N.K., Satyanarayana, A.N.V. and Kumar, B.P. (2013b) Response of upper ocean and impact of barrier layer on Sidr cyclone induced sea surface cooling. Ocean Science Journal, 48(3), 279-288.

Vissa, N.K., Satyanarayana, A.N.V. and Prasad Kumar, B. (2013c) Comparison of mixed layer depth and barrier layer thickness for the Indian Ocean using two different climatologies. International Journal of Climatology, 33(13), 2855-2870.

Weller, R.A., Farrar, J.T., Buckley, J., Mathew, S., Venkatesan, R., Lekha, J.S., Chaudhuri, D., Kumar, N.S. and Kumar, B.P. (2016)
Air-sea interaction in the Bay of Bengal. Oceanography, 29(2), $28-37$.

Wright, R. (1969) Temperature structure across the Kuroshio before and after typhoon Shirley. Tellus, 21, 409-413. https://doi.org/10.1175/ JAS4051.1.

Yan, Y., Li, L. and Wang, C. (2017) The effects of oceanic barrier layer on the upper ocean response to tropical cyclones. Journal of Geophysical Research: Oceans, 122(6), 4829-4844.

Zedler, S.E. (2009) Simulations of the ocean response to a hurricane: nonlinear processes. Journal of Physical Oceanography, 39(10), 2618-2634.

How to cite this article: Busireddy NKR, Ankur K, Osuri KK, Sivareddy S, Niyogi D. The response of ocean parameters to tropical cyclones in the Bay of Bengal. Q J R Meteorol Soc. 2019;1-13. https://doi.org/10.1002/qj.3622 